\title{
ANÁLISIS DE LA SINIESTRALIDAD EN EL SISTEMA DE RIESGOS LABORALES COLOMBIANO: REFLEXIONES DESDE LA ACADEMIA*
}

\author{
ANALYSIS OF WORK ACCIDENT AND \\ OCCUPATIONAL DISEASE RATES IN \\ THE COLOMBIAN LABOR RISK SYSTEM: \\ REFLECTIONS FROM THE ACADEMY
}

\author{
Diana Elizabeth Cuervo-Díaz, MD, PhD** \\ Marisol Moreno-Angarita, PhD*** \\ Fecha de recepción: 20 de febrero de 2017 \\ Fecha de aceptación: 20 de marzo de 2017 \\ Disponible en linea: 30 de noviembre de 2017
}

\section{Para citar este artículo/To cite this article}

\begin{abstract}
Cuervo-Díaz, Diana Elizabeth \& Moreno-Angarita, Marisol, Análisis de la siniestralidad en el sistema de riesgos laborales colombiano: reflexiones desde la academia, 135 Vniversitas, 131-164 (2017). https://doi.org/10.11144/ Javeriana.vj135.assr

doi:10.11144/Javeriana.vj135.assr
\end{abstract}

* Artículo de investigación producto de la fase cuantitativa de la tesis doctoral Prevención y manejo de la discapacidad para trabajar: Un análisis al sistema de riesgos laborales colombiano, para optar al título de doctora en salud pública, Universidad Nacional de Colombia.

** Médica, Pontificia Universidad Javeriana, Bogotá. Especialista en administración de salud ocupacional, Universidad Jorge Tadeo Lozano, Bogotá. Especialista en derecho de seguridad social, Pontificia Universidad Javeriana. Bogotá Doctora en Salud Publica Universidad Nacional de Colombia. Miembro principal de la Junta Nacional de Calificación de Invalidez- Colombia. Profesora de cátedra especializaciones de Derecho de Seguridad Social y Derecho Laboral de la Pontificia Universidad Javeriana Bogotá. Miembro del grupo de investigación Discapacidad, Políticas y Justicia Social Universidad Nacional de Colombia. Contacto: decuervod@unal.edu.co

*** Profesora titular, Facultad de Medicina, Universidad Nacional de Colombia. Consejera de discapacidad, representante de la academia al Consejo Nacional de Discapacidad, CND. Directora del Grupo del grupo de investigación Discapacidad, Políticas y Justicia Social, Universidad Nacional de Colombia. ORCID: http://orcid.org/0000-0002-2468-1491. Fonoaudióloga, Universidad Nacional de Colombia. Máster en comunicación, Pontificia Universidad Javeriana, Bogotá. Doctora en salud pública, Universidad Nacional de Colombia. Estancia posdoctoral, Universidad de Roehampton. Contacto: mmorenoa@unal.edu.co 


\section{RESUMEN}

Este artículo, producto de una investigación, incluye hallazgos de la fase cuantitativa de la tesis doctoral Prevención y manejo de la discapacidad para trabajar: un análisis del sistema de riesgos laborales colombiano. Se realizó un análisis cuantitativo, teniendo en cuenta reflexiones encaminadas a la identificación de retos urgentes. Incluye la información suministrada por la Federación de Aseguradores Colombianos (Fasecolda), gremio que agrupa a las aseguradoras del sistema de riesgos laborales en Colombia, y datos estadísticos obtenidos mediante investigación en la Junta Nacional de Calificación de Invalidez, JNC. Tiene como propósito entender el comportamiento de los accidentes y enfermedades laborales en Colombia y las características sociodemográficas de los pacientes con incapacidad permanente parcial (IPP), con el fin de hacer reflexiones tendientes a servir de insumo en la construcción de política pública en el sistema de riesgos laborales colombiano.

Palabras clave: Siniestralidad; riesgo laboral; accidente de trabajo; enfermedad laboral; discapacidad para trabajar; prevención 


\section{ABSTRACT}

This article is the product of research, includes findings of the quantitative phase of the doctoral thesis work Disability Prevention and Management in the Colombian Labor Risk System. It focusses on the occupational diseases and work accident, shown in data reported by insurance sector, and their respective analysis from the perspective of the work disability prevention and management. A quantitative analysis was carried out, taking into account reflections aimed at the identification of urgent challenges.

Includes the information provided by the Federation of Colombian Insurers (Fasecolda) that groups the insurers of the system of occupational risks in Colombia and statistical data obtained through research at the National Disability Rating Board in Colombia.

Its purpose is to understand the behavior of occupational accidents and diseases in Colombia and the sociodemographic characteristics of patients with partial permanent disability (IPP by the initials in Spanish); in order to make reflections tending to serve as input in the construction of public policy in the system of occupational risks.

Keywords: Rate accident; occupational hazard; work accident; occupational disease; work disability; prevention

\section{SUMARIO}

InTRoducción.- I. ANÁlisis de los DATOS DE LA SINIESTRALIDAD.- II. ¿CUÁLES SON LAS CARACTERÍSTICAS DE LOS CASOS LABORALES CALIFICADOS POR LA Junta Nacional de Calificación de Invalidez, JNC?- $A$. Distribución de eventos según los reclamantes.- B. Correlación de datos de la JNC y los de Fasecolda.- III. CARACTERÍSTICAS SOCIODEMOGRÁFICAS DE LOS CASOS LABORALES CALIFICADOS CON INCAPACIDAD PERMANENTE PARCIAL POR LA Junta NaCional de CALIFICACión de Invalidez 2007-2014. - Bibliografía. 


\section{INTRODUCCIÓN}

El objetivo del artículo es presentar la siniestralidad del Sistema de Riesgos Laborales colombiano, mostrada en cifras reportadas por fuentes pertinentes, y su correspondiente análisis desde la perspectiva de la prevención y manejo de la discapacidad para trabajar. Se usa un análisis cuantitativo y se realizan reflexiones encaminadas a la identificación de retos urgentes.

El Sistema de Riesgos Laborales colombiano está estructurado como un sistema de compensación de responsabilidad objetiva (no culpa), en el cual las aseguradoras de riesgos laborales subrogan el riesgo del empleador y asumen la atención del accidente de trabajo o la enfermedad laboral, una vez se haya comprobado la relación de causalidad entre el trabajo y el evento, sin importar de quién sea la culpa del siniestro'. Para el caso colombiano, está administrado por aseguradoras privadas y Positiva Compañía de Seguros, de capital mixto; este esquema permite obtener ganancias tanto financieras como operacionales a las aseguradoras que participan en la ejecución del sistema, el cual es regulado y vigilado por el Estado.

El Sistema contempla entre los beneficios económicos:

- La incapacidad temporal definida en el artículo 3 de la Ley 776 de 2002 como "el subsidio equivalente al 100\% del salario base de cotización calculado desde el día siguiente al que ocurrió el accidente o se inició la incapacidad hasta el momento de la rehabilitación integral o curación, o de la declaración de la incapacidad permanente parcial, la invalidez o la muerte"2. La prestación se extiende hasta un máximo de 540 días de incapacidad temporal ${ }^{3}$.

1 Gerardo Arenas-Monsalve, El derecho colombiano de la seguridad social [Internet] (Legis, Bogotá, 2011). Disponible en: http://ezproxy.unal.edu.co/login?url=http://search.ebscohost.com/ login.aspx?direct $=$ true $\& \mathrm{db}=$ cat $02704 \mathrm{a} \& \mathrm{AN}=$ unc.000424417\&lang=es\&site=eds-live

2 Colombia, Ley 776 de 2002, por la cual se dictan normas sobre la organización, administración y prestaciones del Sistema General de Riesgos Profesionales, 45.037 Diario Oficial, 17 de diciembre de 2002. Disponible en: http://www.secretariasenado.gov.co/senado/basedoc/ley_0776_2002.html

3 Colombia, Ley 1562 de 2012, por la cual se modifica el Sistema de Riesgos Laborales y se dictan otras disposiciones en materia de salud ocupacional, 48.488 Diario Oficial, 11 de julio de 2012. Disponible en: http://www.secretariasenado.gov.co/senado/basedoc/ley_1562_2012.html. Colombia, Decreto 1352 de 2013, por el cual se reglamenta la organización y funcionamiento de las Juntas de Calificación de Invalidez, y se dictan otras disposiciones, 48.834 Diario Oficial, 27 de junio de 2013. Disponible en: Disponible en: http://www.suin-juriscol.gov.co/viewDocument.asp?id=1271832 
- La incapacidad permanente parcial (IPP), definida en los artículos 7 y 8 de la Ley 776 de 2002, corresponde a una indemnización en proporción al daño sufrido, en suma no inferior a dos salarios base de liquidación, ni superior a 24 veces el salario base de liquidación. Se aplica la tabla única para indemnizaciones por incapacidad permanente parcial $^{4} 5$.

- La pensión por invalidez, definida como una pérdida de capacidad laboral igual o superior al 50\%. En los casos en que el porcentaje es mayor al 50\% y menor del 66\%, la mesada corresponde al $66 \%$ del ingreso base de liquidación; cuando la pérdida de capacidad laboral es mayor al $66 \%$, el ingreso base de liquidación es del $75 \%$.

De otra parte, se considera que entre las prestaciones asistenciales está incluida la rehabilitación integral, que contempla el derecho a la asesoría y acompañamiento para el reintegro laboral con acomodaciones por parte del empleador ${ }^{7}$. Esto significa que, si bien está contemplada dentro de la norma, hay oportunidades para desarrollar políticas de retorno al trabajo que sean efectivas y que contemplen no solo el sector salud, sino que activen todos los sectores involucrados en la inclusión plena.

4 Colombia, Decreto 2644 de 1994, por el cual se expide la Tabla Única para las indemnizaciones por pérdida de la capacidad laboral entre el 5\% y 49.99\% y la prestación económica correspondiente, 41.620 Diario Oficial, 30 de noviembre de 1994. Disponible en: http://www.suin-juriscol.gov.co/ clp/contenidos.dll/Decretos/1475751?fn=document-frame.htm $\$ f=$ templates $\$ 3.0$

5 Colombia, Ley 776 de 2002, por la cual se dictan normas sobre la organización, administración y prestaciones del Sistema General de Riesgos Profesionales, 45.037 Diario Oficial, 17 de diciembre de 2002. JuAn CARlos CoRtés-GonzÁlez, Régimen de los riesgos laborales en Colombia: comentarios a la Ley 1562 de 2012 [Internet] (Legis, Bogotá, 2012). Disponible en: http://ezproxy.unal.edu.co/ login?url=http://search.ebscohost.com/login.aspx?direct=true \&db=cat02704a\&AN=unc.0004558 84\&lang $=$ es\&site $=$ eds-live

6 Colombia, Ley 776 de 2002, por la cual se dictan normas sobre la organización, administración y prestaciones del Sistema General de Riesgos Profesionales, 45.037 Diario Oficial, 17 de diciembre de 2002. JuAn CARlos Cortés-GonzÁlez, Régimen de los riesgos laborales en Colombia: comentarios a la Ley 1562 de 2012 [Internet] (Legis, Bogotá, 2012).

7 Gerardo Arenas-Monsalve, El derecho colombiano de la seguridad social [Internet] (Legis, Bogotá, 2011). Colombia, Ley 776 de 2002, por la cual se dictan normas sobre la organización, administración y prestaciones del Sistema General de Riesgos Profesionales, 45.037 Diario Oficial, 17 de diciembre de 2002. Colombia, Ministerio de la Protección Social, Manual de procedimientos para la rehabilitación y reincorporación ocupacional de los trabajadores en el Sistema General de Riesgos Profesionales (Ministerio de la Protección Social, Bogotá, 2010). Disponible en: http:// fondoriesgoslaborales.gov.co/documents/Publicaciones/Manuales/MANUAL-PARA-REHABILI TACION-2012.pdf. ANA MARÍA GUTIÉRREZ-STRAuSS, Rehabilitación integral y reincorporación: su incidencia en el ausentismo laboral, 12 Revista de la Sociedad Colombiana de Medicina del Trabajo, 1, 8-11 (2009). 
Con el propósito de entender el comportamiento de los accidentes y enfermedades laborales en Colombia y las presentaciones económicas consecuentes, se analizó la información suministrada por la Federación de Aseguradores Colombianos (Fasecolda) que agrupa a las aseguradoras del Sistema de Riesgos Laborales en Colombia ${ }^{8}$. Con corte a marzo de 2014, se publicaron las siguientes estadísticas y otros datos que se presentan a continuación para mostrar el estado evolutivo de la siniestralidad en los datos objeto de este artículo.

Así mismo, se presentan las estadísticas de la Junta Nacional para el período 2007-2014, que fueron obtenidas durante la fase cuantitativa de la tesis doctoral Prevención y manejo de la discapacidad para trabajar: un análisis al sistema de riesgos laborales colombiano. En la primera sección, están los datos encontrados y en la segunda sección se realizan los análisis y discusiones, con el fin de incentivar la reflexión y construcción de futuras líneas de investigación.

\section{Gráfico 1}

\section{Tasa de accidentes de trabajo en el Sistema de Riesgos Laborales AT x 100. Federación de Aseguradores Colombianos, Fasecolda. Corte a marzo de 2014}

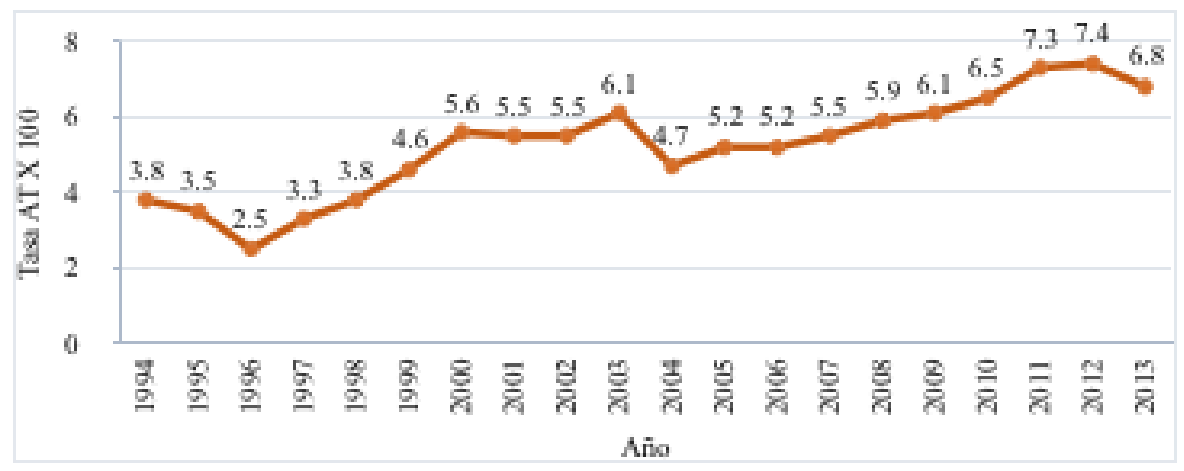

Fuente: Estadísticas presidenciales, información enviada por las compañías. Cálculos Cámara Técnica de Riesgos Laborales - Federación de Aseguradores Colombianos (Fasecolda)

8 Antes de 2009, Fasecolda agrupaba exclusivamente las aseguradoras privadas, razón por la cual no se cuenta con las estadísticas de protección laboral del seguro social. Tras la consolidación de la aseguradora Positiva como empresa de capital mixto — público y privado-y gracias a su vinculación a Fasecolda, es posible contar con estadísticas acumuladas de todo el sector asegurador a partir de esa fecha. 


\section{Tabla 1}

\section{Tasas de siniestralidad}

\begin{tabular}{|l|c|c|c|c|c|c|c|}
\hline \multicolumn{7}{|c|}{ Tasas nacionales 2008-2014 } & $\mathbf{2 0 1 2}$ \\
\hline & $\mathbf{2 0 0 8}$ & $\mathbf{2 0 0 9}$ & $\mathbf{2 0 1 0}$ & $\mathbf{2 0 1 1}$ & $\mathbf{2 0 1 2}$ & $\mathbf{2 0 1 3}$ & $\mathbf{2 0 1 4}$ \\
\hline $\begin{array}{l}\text { Tasa de AT por cada } \\
100.000 \text { trabajadores }\end{array}$ & 27,94 & 6,02 & 6,61 & 7,41 & 7,82 & 7,53 & 7,71 \\
\hline $\begin{array}{l}\text { Tasa de EL por cada } \\
100.000 \text { trabajadores }\end{array}$ & 95,66 & 89,69 & 130,65 & 110,37 & 119,24 & 114,64 & 108,65 \\
\hline $\begin{array}{l}\text { Tasa de muertes calificadas } \\
\text { por AT por cada 100.000 } \\
\text { trabajadores }\end{array}$ & 9,25 & 8,75 & 10,11 & 9,23 & 8,02 & 8,53 & 6,31 \\
\hline $\begin{array}{l}\text { Tasa de muertes calificadas } \\
\text { por EL por cada 100.000 } \\
\text { trabajadores }\end{array}$ & 0,02 & 0,00 & 0,03 & 0,01 & 0,02 & 0,02 & 0,06 \\
\hline $\begin{array}{l}\text { Tasa de indemnizaciones } \\
\text { IPP por AT por cada } \\
\text { 100.000 trabajadores }\end{array}$ & 95,25 & 90,39 & 129,27 & 105,03 & 116,98 & 108,09 & 117,20 \\
\hline $\begin{array}{l}\text { Tasa de indemnizaciones } \\
\text { IPP por EL por cada } \\
\text { 100.000 trabajadores }\end{array}$ & 16,77 & 17,76 & 33,68 & 29,96 & 35,94 & 34,84 & 39,53 \\
\hline
\end{tabular}

Fuente: Estadísticas presidenciales, información enviada por las compañías. Cálculos Cámara Técnica de Riesgos Laborales - Federación de Aseguradores Colombianos (Fasecolda)

AT: accidente de trabajo. EL: enfermedad laboral. IPP: incapacidad permanente parcial.

\section{Gráfico 2}

\section{Tasa de enfermedad laboral en el Sistema de Riesgos Laborales EL x 100.000. Federación de Aseguradores Colombianos, Fasecolda. Corte a marzo de 2014}

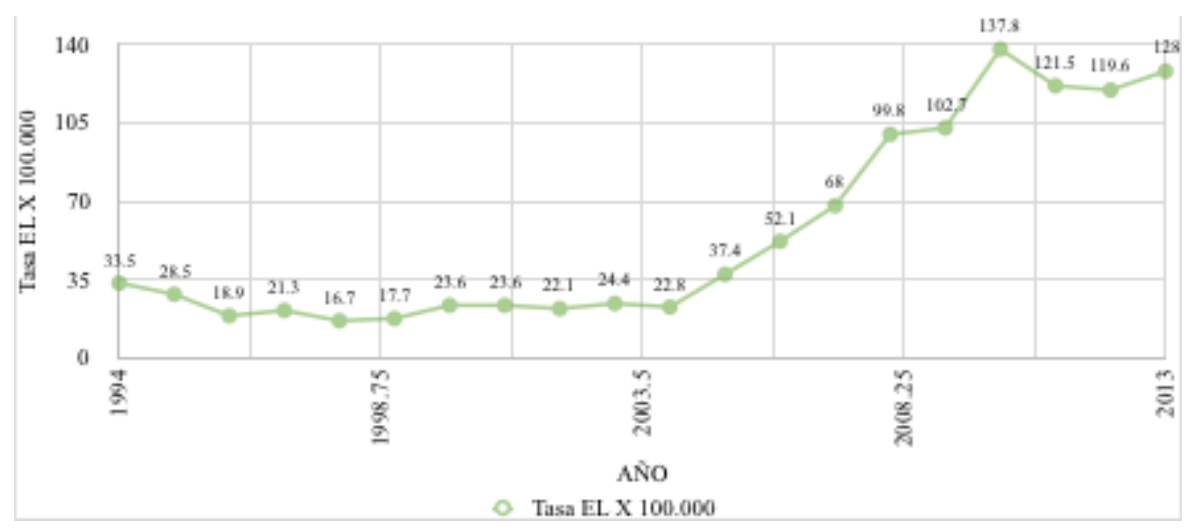

Fuente: Estadísticas presidenciales, información enviada por las compañías. Cálculos Cámara Técnica de Riesgos Laborales - Federación de Aseguradores Colombianos (Fasecolda) 


\section{Tabla 2}

\section{Análisis de siniestralidad en el Sistema de Riesgos Laborales, período 2009-2013}

\begin{tabular}{|l|c|c|c|c|c|}
\hline & $\mathbf{2 0 0 9}$ & $\mathbf{2 0 1 0}$ & $\mathbf{2 0 1 1}$ & $\mathbf{2 0 1 2}$ & $\mathbf{2 0 1 3}$ \\
\hline Total trabajadores & 6.700 .837 & 6.813 .597 & 7.499 .380 & 8.431 .782 & 8.269 .951 \\
\hline $\begin{array}{l}\text { Enfermedades laborales (EL) } \\
\text { calificadas }\end{array}$ & 6.068 & 8.293 & 7.826 & 9.524 & 10.189 \\
\hline $\begin{array}{l}\text { Accidentes de trabajo (AT) } \\
\text { calificados }\end{array}$ & 404.552 & 437.218 & 540.597 & 609.881 & 542.406 \\
\hline Muertes calificadas AT & 588 & 497 & 378 & 530 & 750 \\
\hline Muertes calificadas EL & 0 & 2 & 1 & 2 & 2 \\
\hline Total muertes calificadas & 588 & 499 & 379 & 532 & 752 \\
\hline Pensiones de invalidez AT & 250 & 210 & 163 & 217 & 214 \\
\hline Pensiones de invalidez EL & 17 & 20 & 17 & 33 & 34 \\
\hline Total pensiones de invalidez & 267 & 230 & 180 & 250 & 248 \\
\hline $\begin{array}{l}\text { Indemnizaciones por IPP } \\
\text { pagadas AT }\end{array}$ & 6.070 & 7.559 & 7.804 & 9.672 & 8.748 \\
\hline $\begin{array}{l}\text { Indemnizaciones por IPP } \\
\text { pagadas EL }\end{array}$ & 1.201 & 2.093 & 2.187 & 2.987 & 2.836 \\
\hline $\begin{array}{l}\text { Total indemnizaciones IPP } \\
\text { pagadas }\end{array}$ & 7.271 & 9.552 & 9.991 & 12.659 & 11.584 \\
\hline
\end{tabular}

Fuente: Estadísticas presidenciales, información enviada por las compañías. Cálculos Cámara Técnica de Riesgos Laborales - Federación de Aseguradores Colombianos (Fasecolda)

AT: accidente de trabajo. EL: enfermedad laboral. IPP: incapacidad permanente parcial. $\uparrow:$ muertes. 
Gráfico 3

Distribución de número de casos por reclamante ante la Junta Nacional de Calificación de Invalidez, JNC, 2007 a 2014

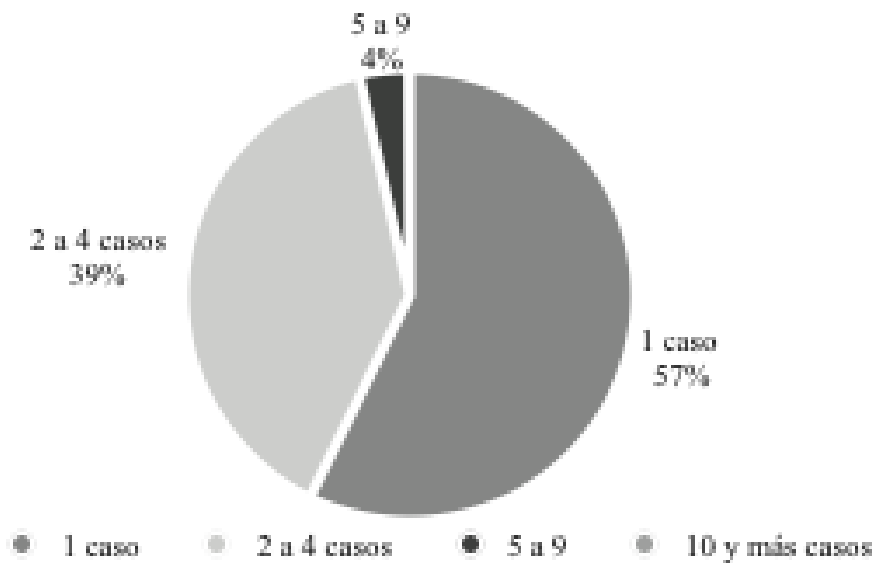

Fuente: elaboración propia, estadísticas de la Junta Nacional de Calificación 2007-2014, Tesis doctoral Prevención y manejo de la discapacidad para trabajar: un análisis del sistema de riesgos laborales colombiano

\section{Gráfico 4}

Distribución de eventos laborales según edad del reclamante ante la Junta Nacional de Calificación de Invalidez, JNC, 2007 a 2014

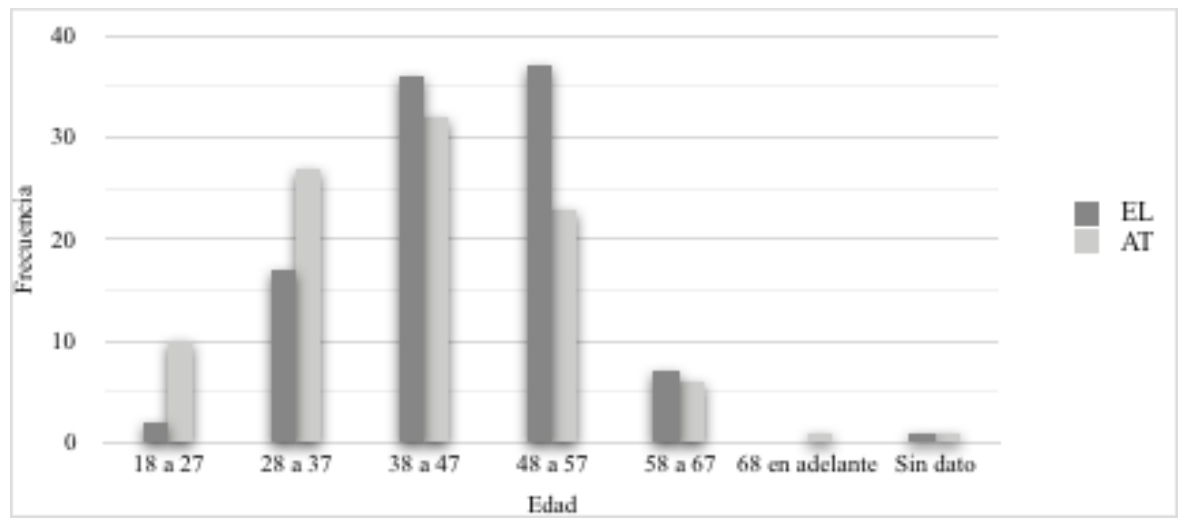

Fuente: elaboración propia, estadísticas de la Junta Nacional de Calificación 2007-2014, Tesis doctoral Prevención y manejo de la discapacidad para trabajar: un análisis del sistema de riesgos laborales colombiano 


\section{Gráfico 5}

Distribución de casos de eventos laborales según nivel educativo del reclamante ante la Junta Nacional de Calificación de Invalidez, JNC, 2007 a 2014

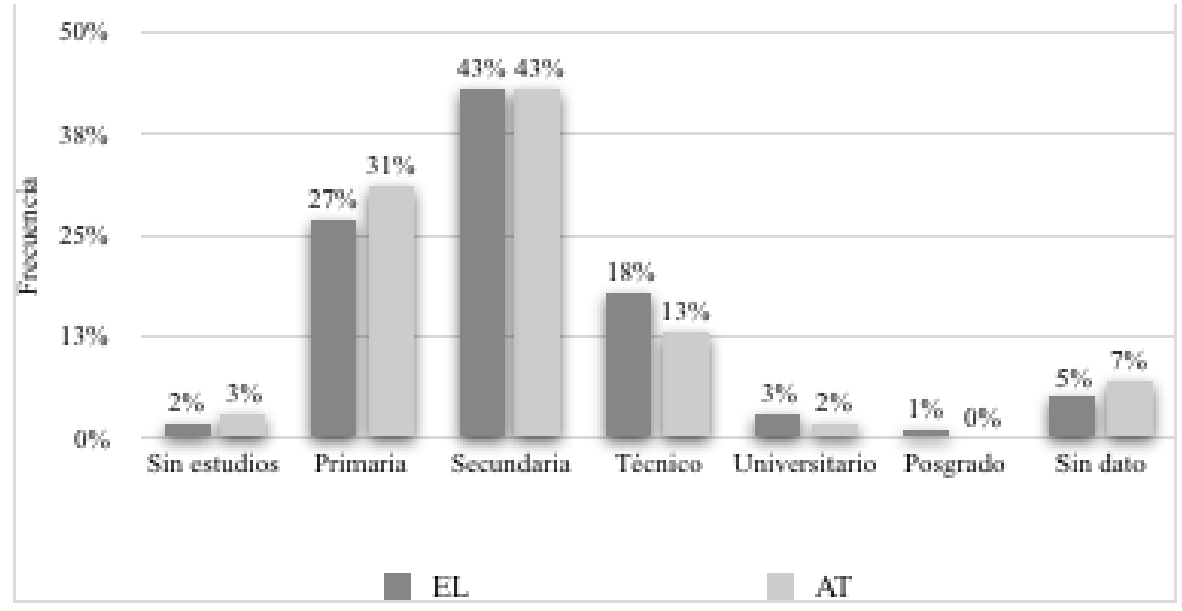

Fuente: elaboración propia, estadísticas de la Junta Nacional de Calificación 2007-2014, Tesis doctoral Prevención y manejo de la discapacidad para trabajar: un análisis del sistema de riesgos laborales colombiano

\section{Gráfico 6}

Distribución de casos de eventos laborales según tipo de cargo del reclamante ante la Junta Nacional de Calificación de Invalidez, JNC, 2007 a 2014

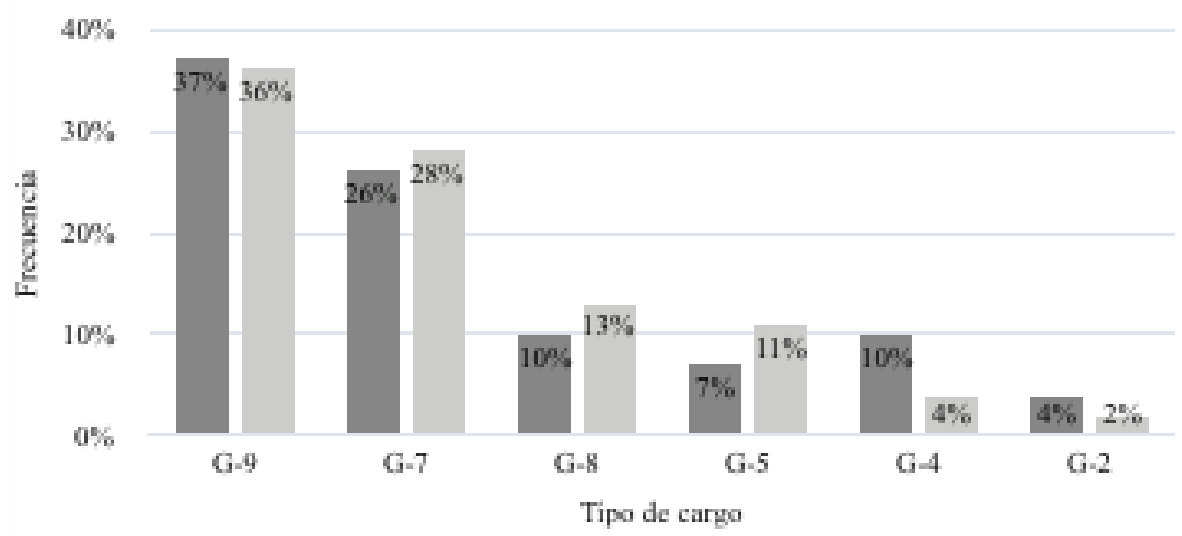

EL. 


\section{Tabla 3}

\section{Agrupación de cargos de la Clasificación Internacional Uniforme de Ocupaciones CIUO-08}

\begin{tabular}{|l|l|}
\hline G-9 & $\begin{array}{l}\text { Ocupaciones elementales: limpiadores, peones (agrícolas, minería, } \\
\text { construcción), ayudantes, recolectores de desechos, vendedores ambulantes } \\
\text { y afines }\end{array}$ \\
\hline G-8 & Operadores de maquinaria, ensambladores, conductores \\
\hline G-7 & $\begin{array}{l}\text { Oficiales y operarios de construcción y metalurgia, artes gráficas, } \\
\text { electricidad, alimentos, confección }\end{array}$ \\
\hline G-6 & Trabajadores agrícolas y forestales calificados \\
\hline G-5 & Trabajadores de comercio, cuidados personales y protección y seguridad \\
\hline G-4 & $\begin{array}{l}\text { Personal de apoyo administrativo: oficinistas, analistas, trato directo con el } \\
\text { público }\end{array}$ \\
\hline G-3 & $\begin{array}{l}\text { Profesionales y técnicos de nivel medio de la salud, financieros, jurídicos, } \\
\text { comunicación y cultural }\end{array}$ \\
\hline G-2 & Profesionales, científicos, intelectuales \\
\hline G-1 & $\begin{array}{l}\text { Personal directivo, administración pública, poder ejecutivo y legislativo, } \\
\text { gerentes }\end{array}$ \\
\hline G-0 & Oficiales, suboficiales y otros miembros de las fuerzas armadas \\
\hline
\end{tabular}

Fuente: elaboración propia, estadísticas de la Junta Nacional de Calificación 2007-2014, Tesis doctoral Prevención y manejo de la discapacidad para trabajar: un análisis del sistema de riesgos laborales colombiano

\section{Gráfico 7}
Distribución de eventos laborales según género del reclamante ante la Junta Nacional de Calificación de Invalidez, JNC, 2007 a 2014

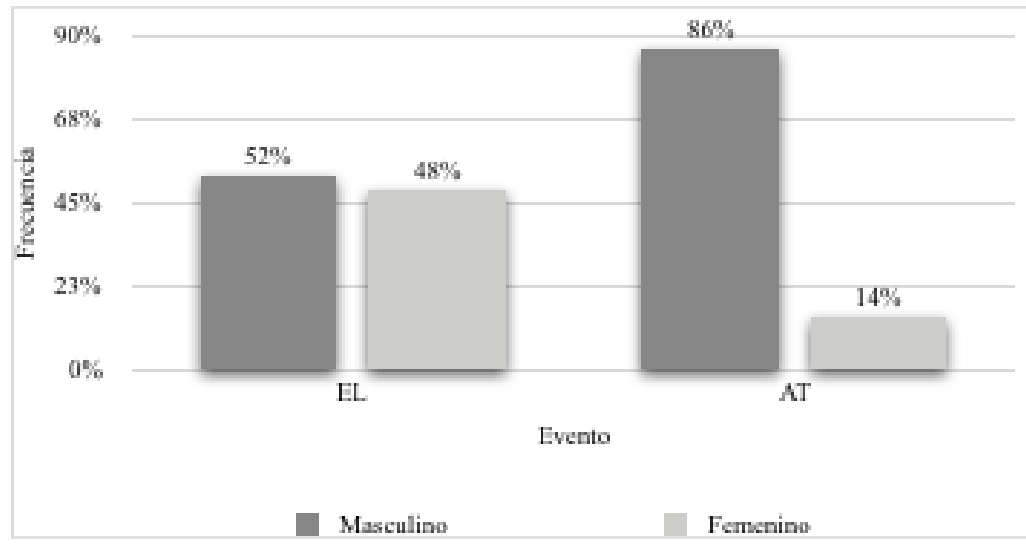

Fuente: elaboración propia, estadísticas de la Junta Nacional de Calificación 2007-2014, Tesis doctoral Prevención y manejo de la discapacidad para trabajar: un análisis del sistema de riesgos laborales colombiano 


\section{Gráfico 8}

Distribución de casos de enfermedad laboral del sistema osteomuscular. Junta Nacional de Calificación de Invalidez, JNC, 2007 a 2014

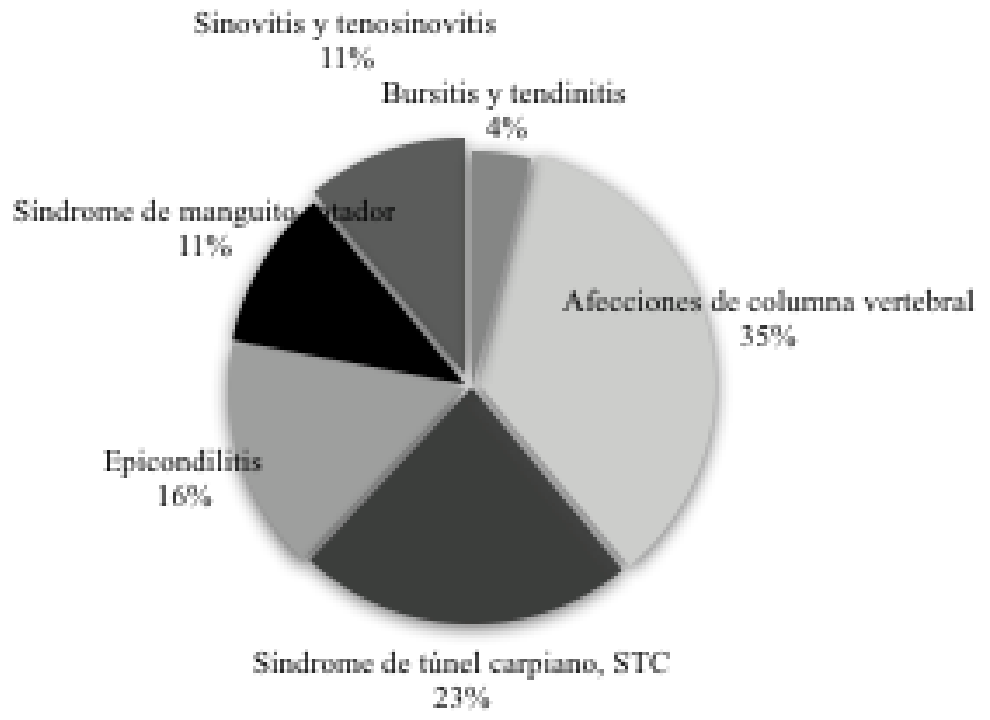

Fuente: elaboración propia, estadísticas de la Junta Nacional de Calificación 2007-2014, Tesis doctoral Prevención y manejo de la discapacidad para trabajar: un análisis del sistema de riesgos laborales colombiano 


\section{Gráfico 9}

Distribución de casos de eventos laborales según actividad económica de empresa. Junta Nacional de Calificación de Invalidez, JNC, 2007 a 2014

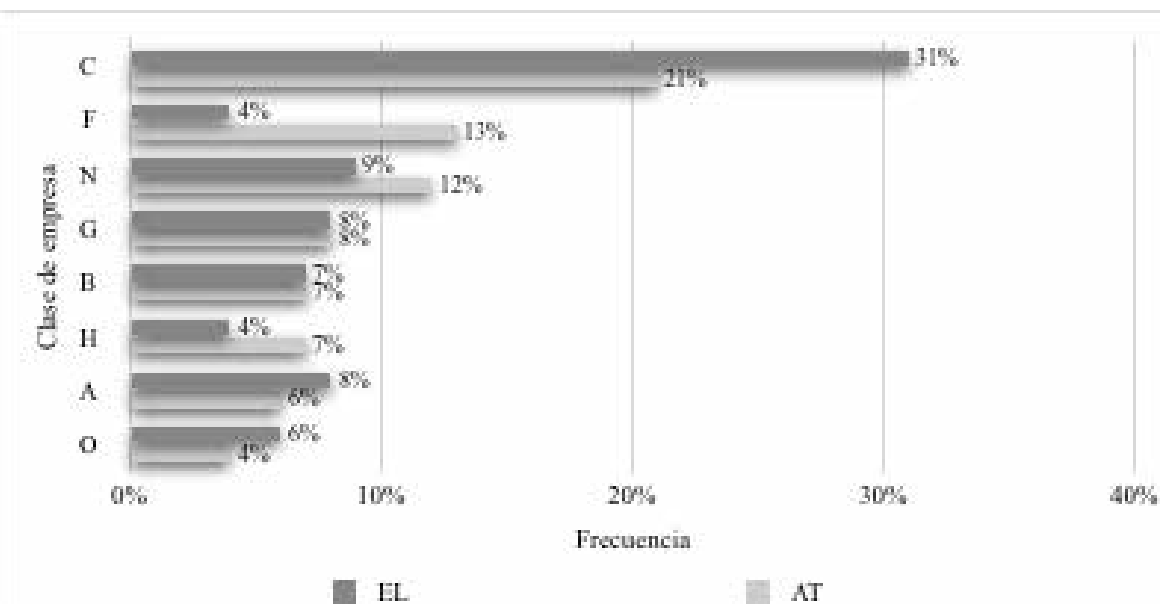

Fuente: elaboración propia, estadísticas de la Junta Nacional de Calificación 2007-2014, Tesis doctoral Prevención y manejo de la discapacidad para trabajar: un análisis del sistema de riesgos laborales colombiano

Convenciones: A: Empresas de producción agrícola. B: Compañías de explotación minera, petroleras y canteras. C: Industrias manufactureras. F: Empresas de construcción. G: Empresas dedicadas al comercio y/o reparación de vehículos. H: Empresas de transporte y almacenamiento. N: Empresas de suministro de personal de apoyo. O: Entidades de administración pública y defensa 


\section{Gráfico 10}

Distribución de casos de lesiones por accidente de trabajo. Junta Nacional de Calificación de Invalidez, JNC, 2007 a 2014

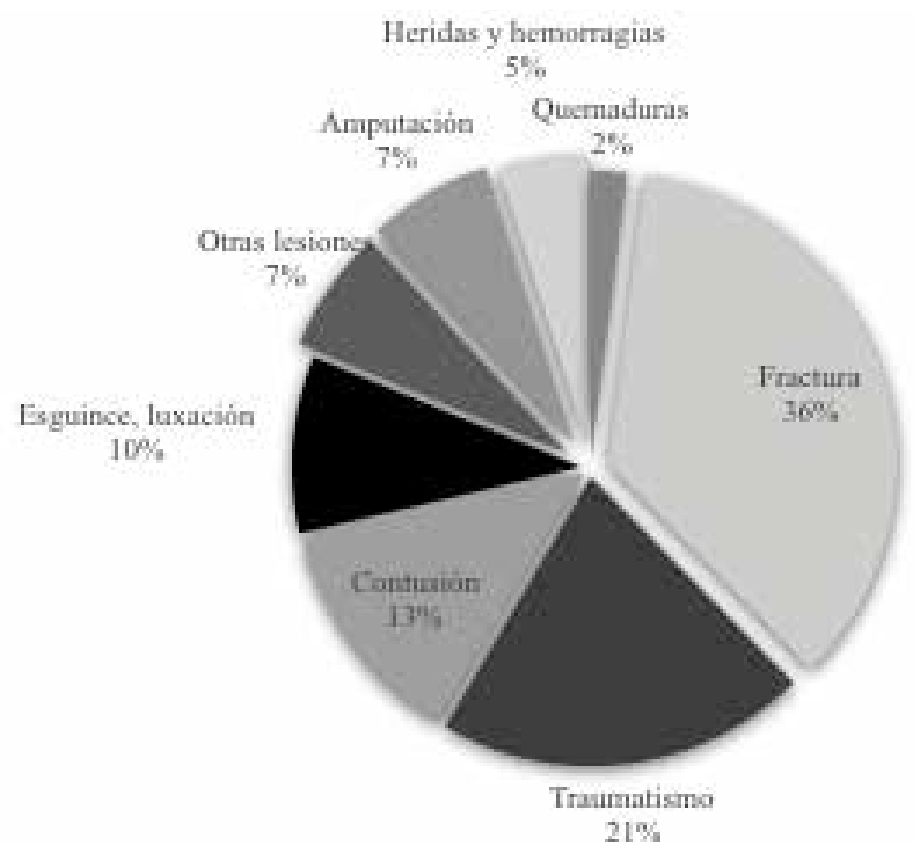

Fuente: elaboración propia, estadísticas de la Junta Nacional de Calificación 2007-2014, Tesis doctoral Prevención y manejo de la discapacidad para trabajar: un análisis del sistema de riesgos laborales colombiano 


\section{Gráfico 11}

Distribución de calificados con IPP según actividad económica de la empresa a la que pertenece el reclamante. Junta Nacional de Calificación de Invalidez, JNC, 2007 a 2014

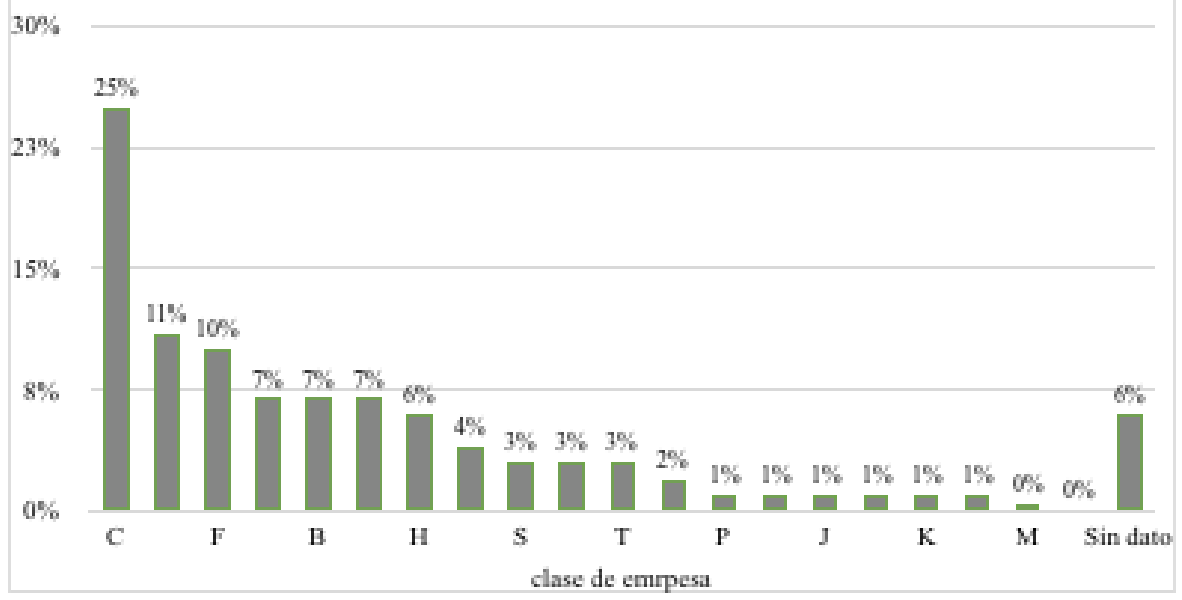

Fuente: elaboración propia, estadísticas de la Junta Nacional de Calificación 2007-2014, Tesis doctoral Prevención y manejo de la discapacidad para trabajar: un análisis del sistema de riesgos laborales colombiano

\section{Tabla 4}

\section{Actividades económicas}

\begin{tabular}{|l|l|l|}
\hline $\begin{array}{l}\text { A: Agricultura, ganadería, } \\
\text { caza, silvicultura }\end{array}$ & $\begin{array}{l}\text { H: Transporte y } \\
\text { almacenamiento }\end{array}$ & $\begin{array}{l}\text { O: Administración pública } \\
\text { y defensa }\end{array}$ \\
\hline $\begin{array}{l}\text { B: Explotación de minas, } \\
\text { canteras y petróleo }\end{array}$ & $\begin{array}{l}\text { I: Servicios de alojamiento } \\
\text { y comida }\end{array}$ & P: Educación \\
\hline $\begin{array}{l}\text { C: Industrias } \\
\text { manufactureras }\end{array}$ & $\begin{array}{l}\text { J: Información y } \\
\text { comunicaciones }\end{array}$ & $\begin{array}{l}\text { Q: Atención de salud } \\
\text { humana y asistencia social }\end{array}$ \\
\hline $\begin{array}{l}\text { D: Suministro de } \\
\text { electricidad, gas, vapor y } \\
\text { aire acondicionado }\end{array}$ & $\begin{array}{l}\text { K: Actividades financieras } \\
\text { y de seguros }\end{array}$ & $\begin{array}{l}\text { R: Actividades artísticas, } \\
\text { entretenimiento y } \\
\text { recreación }\end{array}$ \\
\hline $\begin{array}{l}\text { E: Distribución de agua, } \\
\text { gestión de desechos y } \\
\text { saneamiento }\end{array}$ & $\begin{array}{l}\text { L: Actividades } \\
\text { inmobiliarias }\end{array}$ & $\begin{array}{l}\text { S: Otras actividades de } \\
\text { servicios }\end{array}$ \\
\hline F: Construcción & $\begin{array}{l}\text { M: Actividades } \\
\text { profesionales, científicas y y } \\
\text { técnicas }\end{array}$ & $\begin{array}{l}\text { T: Hogares individuales en } \\
\text { calidad de empleadores }\end{array}$ \\
\hline $\begin{array}{l}\text { G: Comercio, reparación } \\
\text { de vehículos }\end{array}$ & $\begin{array}{l}\text { N: Servicios } \\
\text { administrativos y de } \\
\text { apoyo }\end{array}$ & $\begin{array}{l}\text { U: Organizaciones } \\
\text { y entidades } \\
\text { extraterritoriales }\end{array}$ \\
\hline
\end{tabular}

Fuente: elaboración propia 


\section{Tabla 5}

Proporción de casos de la Junta Nacional de

Calificación de Invalidez, JNC, con relación a los casos registrados por Fasecolda, 2007 a 2014

\begin{tabular}{|l|c|c|c|}
\hline \multicolumn{1}{|c|}{ Evento } & $\begin{array}{c}\text { Número de casos } \\
\text { en Fasecolda }\end{array}$ & $\begin{array}{c}\text { Número de } \\
\text { casos en JNC }\end{array}$ & Proporción \\
\hline Enfermedad laboral & 61.220 & 20.773 & $34 \%$ \\
\hline Accidente de trabajo & 4.033 .189 & 20.935 & $1 \%$ \\
\hline IPP & 77.476 & 22.660 & $29 \%$ \\
\hline Invalidez & 2.919 & 1.422 & $49 \%$ \\
\hline Muerte & 4.645 & 155 & $3 \%$ \\
\hline
\end{tabular}

Fuente: elaboración propia

\section{Gráfico 12}

Distribución de personas con IPP según nivel de escolaridad del reclamante. Junta Nacional de Calificación de Invalidez, JNC, 2007 a 2014

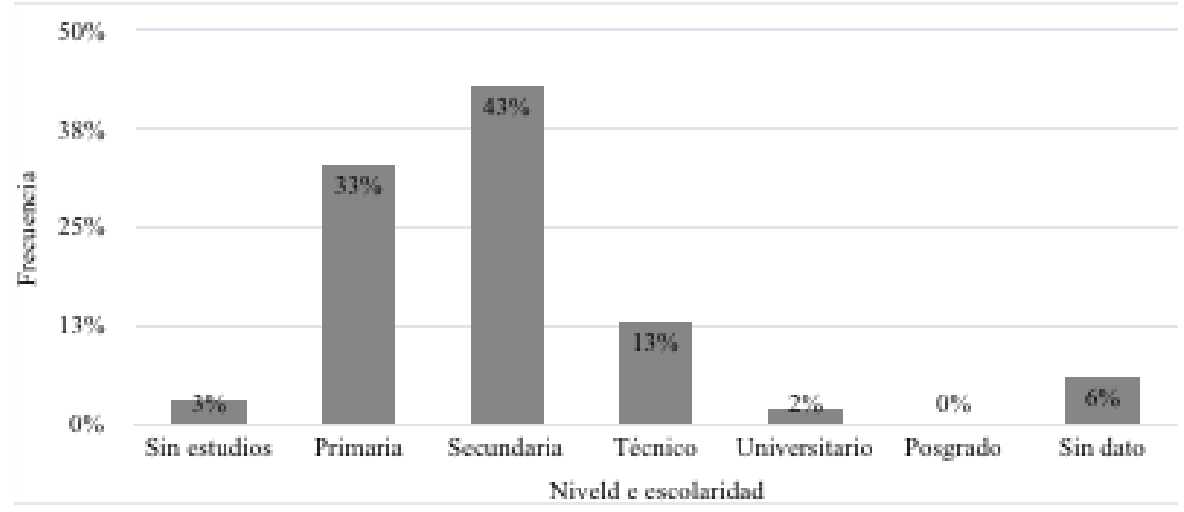

Fuente: elaboración propia 


\section{Gráfico 13}

Distribución de personas con IPP según edad al momento de la notificación. Junta Nacional de Calificación de Invalidez, JNC, 2007 a 2014

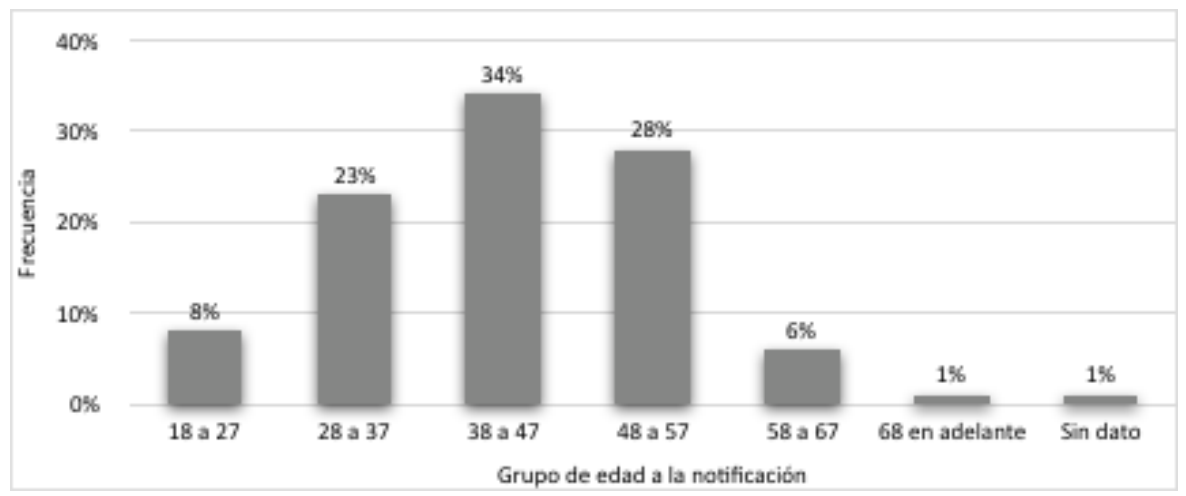

Fuente: elaboración propia

\section{Gráfico 14}

Distribución de personas calificadas con IPP según estado civil del reclamante. Junta Nacional de Calificación de Invalidez, JNC, 2007 a 2014

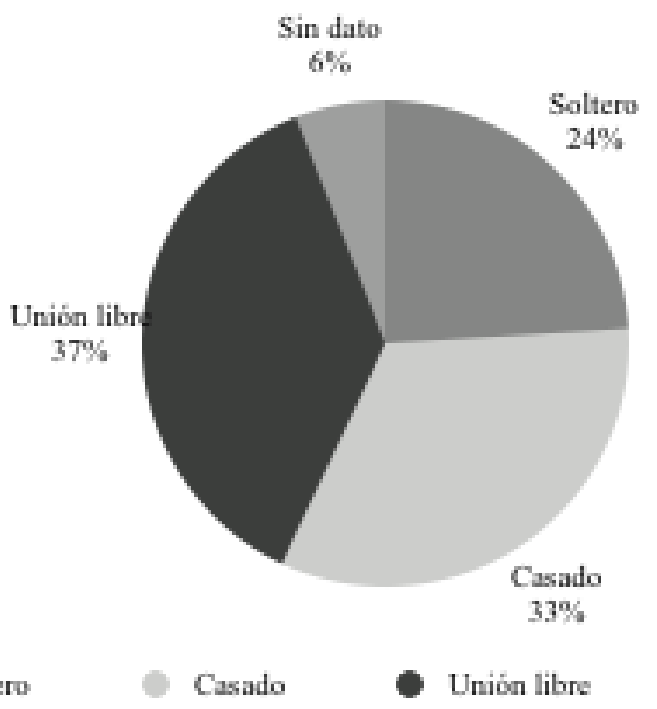




\section{ANÁLISIS DE LOS DATOS DE LA SINIESTRALIDAD}

Como se pudo observar en los gráficos 1, 2 y 3 y las tablas 1, 2 y 3 , se analizó la tasa de accidentalidad entre 1998 y 2013 que, si bien ha aumentado, este aumento no ha sido exponencial como ha sucedido con la enfermedad laboral. Lo anterior puede deberse, entre otras cosas, a que, desde el inicio del sistema, la identificación y calificación como accidente de trabajo ha sido más fácil para los trabajadores y los empleadores, lo que ha facilitado el reporte ante las aseguradoras de riesgos laborales (gráfico 1).

En el período 1994-2013, al comparar el comportamiento de la tasa de enfermedad laboral y accidente de trabajo, desde el inicio del Sistema de Riesgos Laborales, se encontró que la tasa de enfermedad laboral se incrementó de 33,5/100.000 trabajadores para 1994 a 128/100.000 en 2013. Esto se explica porque en los inicios del Sistema de Riesgos Laborales, había poco reporte de enfermedad laboral por el subdiagnóstico y el subregistro de enfermedad laboral, que si bien aún continúa, ha disminuido debido al mayor conocimiento de los trabajadores, empleadores, médicos de las Instituciones Prestadoras de Servicios de Salud y Empresas Promotoras de Salud ${ }^{10}$ (gráfico 1). Podría pensarse que efectivamente hay un fortalecimiento progresivo del Sistema de Riesgos, por parte de todos los actores.

Un ejemplo de esto se encuentra en 2005, fecha en la cual el Ministerio de la Protección Social capacitó en diagnóstico de enfermedad profesional a 650 médicos de todo el país; se identificó un claro aumento en la tasa de enfermedad laboral ${ }^{11}{ }^{12}$.

9 Alba Lucía Vélez-Arango, Salud y enfermedad: la contribución de la Corte Constitucional de Colombia, 17 Hacia la Promoción de la Salud, 2, 91-109. Disponible en: http://ezproxy.unal.edu. $\mathrm{co} / \operatorname{login}$ ?url=http://search.ebscohost.com/login.aspx?direct=true\&db=a9h\&AN=90416424\&lang =es\&site=eds-live, http://www.scielo.org.co/pdf/hpsal/v17n2/v17n2a07.pdf

10 Colombia, Federación de Aseguradores Colombianos, Fasecolda, Enfermedad laboral en Colombia. Debate en Salud Pública sobre enfermedad laboral (Federación de Aseguradores Colombianos, Fasecolda, Bogotá, 2013).

11 Alba Lucía Vélez-Arango, Salud y enfermedad: la contribución de la Corte Constitucional de Colombia, 17 Hacia la Promoción de la Salud, 2, 91-109.

12 Marisol Moreno-Angarita, Sara Ximena Rubio \& Diana Cristina Angarita-Rodríguez, Valoración de la pérdida de la capacidad laboral y ocupacional en Colombia: antecedentes, realidades y perspectivas de actualización [Internet] (Universidad Nacional de Colombia y Ministerio de la Protección Social, Bogotá, 2011). Disponible en: http://ezproxy.unal.edu.co/login?url=http://search. ebscohost.com $/ \operatorname{login}$.aspx?direct $=$ true $\& d b=$ cat02704a\&AN=unc. $000669841 \&$ lang=es \&site $=$ eds-1 
Al comparar el período 2008-2013, es evidente un aumento constante del número de enfermedades laborales calificadas. Esto se puede comprender como resultante de diversos factores: mayor empoderamiento de los líderes de los programas de salud y seguridad en el trabajo, mayor conocimiento de parte de los trabajadores, sindicatos y empresas promotoras de salud, al igual que una mayor divulgación de las normativas relacionadas.

De otra parte, también aumentó el número de casos de invalidez e incapacidad permanente parcial por enfermedad laboral, lo que nos permite preguntarnos: ¿Será que la severidad de los eventos es mayor? ¿Será que en Colombia los programas de riesgos laborales no están siendo efectivos? O ¿será que las posibilidades de que se logre el reintegro o de que el trabajador mantenga su trabajo, después de ocurrir un evento laboral, dependen de otros aspectos, más allá del sector salud?

Hasta 2012, el número de personas con Incapacidad Permanente Parcial por accidente de trabajo fue creciente, con una caída en las cifras para 2013, lo cual coincidió con la disminución de trabajadores afiliados al Sistema General de Riesgos Laborales durante $2013^{13}$.

Respecto al número de personas a quienes se les dictaminó invalidez secundaria a accidente de trabajo y enfermedad laboral, su aumento ha sido proporcional al de la tasa de ocurrencia. Este indicador permite cuestionar a los actores del sistema acerca del impacto, entre otros, de los programas de rehabilitación sobre la prevención de la discapacidad. Estos datos se convierten en evidencia que da un mayor sustento a la necesidad de enfocar los esfuerzos investigativos hacia esta población ${ }^{14}$.

Se aclara que al consultar las cifras de Fasecolda a febrero de 2016, con el fin de actualizar los datos, se encontró que se realizaron cambios en las estadísticas, que si bien en número no son considerables, dejan un interrogante sobre la confiabilidad de las cifras que

ive, http://www.bdigital.unal.edu.co/42924/1/saraximenarubio.2011.pdf

13 Colombia, Federación de Aseguradores Colombianos, Fasecolda, Enfermedad laboral en Colombia. Debate en Salud Pública sobre enfermedad laboral (Federación de Aseguradores Colombianos, Fasecolda, Bogotá, 2013).

14 Colombia, Federación de Aseguradores Colombianos, Fasecolda, Enfermedad laboral en Colombia. Debate en Salud Pública sobre enfermedad laboral (Federación de Aseguradores Colombianos, Fasecolda, Bogotá, 2013). 
maneja el país. Este aspecto es congruente con lo reportado por la Organización Iberoamericana de Salud en su informe de 2012 sobre siniestralidad de los países miembros, en el que menciona que falta mayor disgregación de las estadísticas y presentar en tasas los indicadores ${ }^{15}$. Esta observación fue uno de los aspectos que motivaron el análisis cuantitativo que se presenta en este artículo.

Es importante mencionar que las estadísticas de Fasecolda dan énfasis al tema compensatorio sobre frecuencias de indemnizaciones o gastos en atención, pero no hay reportes respecto al número de pacientes que después de sufrir un accidente de trabajo pudieron retornar a su trabajo (ya sea a su trabajo habitual, con restricciones definitivas o con reubicación laboral, ATEL Reintegrado), tampoco sobre cuáles fueron despedidos o tienen incapacidad laboral prolongada con un vínculo laboral activo, pero sin posibilidad de que regresen al trabajo. Es decir, en nuestro esquema de riesgos laborales, hay una primacía de la compensación económica sobre los resultados del reintegro laboral, que sería, en últimas, el objetivo de la rehabilitación integral en los casos de accidente de trabajo o enfermedad laboral.

Como el país no cuenta con otras estadísticas unificadas en un sistema de información para el sistema de riesgos laborales, como lo contempla la Ley 1562 de 2012, se consideró que debido a que una de las autoras es miembro principal de la Junta Nacional de Calificación de Invalidez, era una oportunidad de aportar al país una visión de las características de los casos de riesgos laborales allí calificados, con el fin de que sirvieran para el análisis y reflexión sobre las futuras políticas y la ejecución del Plan Nacional de Seguridad y Salud en el Trabajo 2013-2021 ${ }^{16}$.

Se aclara que hasta octubre de 2015 la Junta Nacional de Calificación de Invalidez ${ }^{17}$ utilizó la aplicación Diamante, suministrada

15 Organización Iberoamericana de Seguridad Social, OISS, Recopilación de los principales indicadores de siniestralidad laboral y enfermedad ocupacional utilizados en Iberoamérica (2012). Disponible en: http://www.oiss.org/estrategia/IMG/pdf/Informe_sobre_siniestralidad.pdf

16 Colombia, Ministerio del Trabajo, Plan Nacional de Seguridad y Salud en el Trabajo 2013-2021 (Ministerio del Trabajo, Bogotá, 2014). Disponible en: http://www.oiss.org/IMG/pdf/PlanNacional DeSeguridadySaludEnElTrabajo.pdf

17 El Decreto 917 de 1999, Manual Único de Calificación de Invalidez, fue reemplazado por el Decreto 1507 de 2014, que entró en vigencia a partir del 12 de febrero de 2015. La Junta Nacional de Calificación conoció los primeros casos en apelación calificados con el Decreto 1507 de 2014 a partir del segundo semestre de 2015, cuando inició el uso de una nueva aplicación de calificación. Colombia, Decreto 917 de 1999, por el cual se modifica el Decreto 692 de 1995, 43.601 Diario Oficial, 9 de junio 
por el Ministerio del Trabajo hacia finales de 2006. Esta aplicación permitía expedir los dictámenes, pero no era posible realizar informes estadísticos de los casos presentados ante la Junta Nacional, razón por la cual para esta investigación los datos se extrajeron de esta base de datos y se procesaron para obtener las estadísticas que se analizan a continuación.

De 2007 a 2014, la Junta Nacional de Calificación de Invalidez recibió 78.920 reclamaciones, correspondientes a 44.954 personas de todo el país. De estos reclamantes, más de la mitad (57,3\%) presentó un único caso. Esto quiere decir que el $43 \%$ de las personas acudió a la Junta Nacional en más de una ocasión.

Estos hallazgos se explican porque un trabajador puede acudir en una primera ocasión a que se defina el origen de la condición de salud, y en una segunda calificación se determina la pérdida de capacidad laboral; pero también es una medida indirecta que hay una población de trabajadores que busca revisión (recalificación) de la pérdida de capacidad laboral probablemente porque no solo hay deterioro clínico, sino imposibilidad de retornar al trabajo.

Esta tendencia obliga a que se mire con mayor detalle lo que estas cifras pueden mostrar y, aunque el propósito no es generalizar, sí pueden reflejar un importante panorama que debe obligarnos a reflexionar al respecto.

\section{II. ¿CUÁLES SON LAS CARACTERÍSTICAS DE LOS CASOS LABORALES CALIFICADOS POR LA JUNTA NACIONAL DE CALIFICACIÓN DE INVALIDEZ, JNC?}

En el período 2007-2014, entre los trámites remitidos a la JNC, se encontraron 22.655 casos con evento laboral (accidente de trabajo o enfermedad laboral), correspondientes a 13.890 personas, que fueron calificados con una pérdida de capacidad laboral mayor al $5 \%$ y menor al 49,9\% incapacidad permanente parcial (IPP). Los

de 1999. Disponible en: http://www.suin-juriscol.gov.co/viewDocument.asp?id=1798298. Colombia, Decreto 1507 de 2014, por el cual se expide el Manual Único para la Calificación de la Pérdida de la Capacidad Laboral y Ocupacional, 49.241 Diario Oficial, 12 de agosto de 2014. Disponible en: http://www.suin-juriscol.gov.co/clp/contenidos.dll/Decretos/30030556? fn=document-frame. htm $\$ \mathrm{f}=$ templates $\$ 3.0$ 
perfiles que se describen a continuación hacen referencia a las personas, no a los casos.

En los casos de accidente de trabajo, el 86\% de los reclamantes corresponde a hombres, mientras que en las enfermedades laborales el mayor porcentaje corresponde a las mujeres (52\%), aunque en este caso la brecha entre los sexos es menor. Este hallazgo corrobora lo planteado por otros estudios, según los cuales hay una mayor tasa de enfermedad laboral en el sexo femenino asociada con las actividades económicas en las que hay movimientos repetitivos, principalmente desempeñadas por mujeres ${ }^{18}$.

Por grupo de edad, la proporción de accidentes es mayor a la de enfermedades en las personas de 18 a 37 años, mientras que las enfermedades superan a los accidentes en el colectivo de 38 a 57. Esto puede deberse, de una parte, a que a los jóvenes se les ofrecen mayores riesgos, y de otra, a que el envejecimiento cumple un rol importante en la aparición de enfermedades.

\section{A. Distribución de eventos según los reclamantes}

En los reclamantes con enfermedad laboral (EL) se observan mayores proporciones en niveles educativos superiores (técnicos, universitarios y posgrado) que en los que reclaman accidentes de trabajo.

Lo anterior orienta a que el modelo de rehabilitación integral que tiene previsto el Plan Nacional de Seguridad y Salud en el Trabajo, debe tener un enfoque diferencial no solo en cuanto a factores de riesgo, condiciones de salud, sino también respecto a las opciones brindadas para la consecución de un nuevo empleo o la posibilidad de contar con orientación ocupacional, en los casos en los que no es factible que el trabajador continúe en la misma empresa en la que ocurrió el accidente o la enfermedad.

Para las variables de tipo de cargo y clase de empresa, se grafican únicamente los grupos con más altas frecuencias.

Según la labor desempeñada, los cargos de ocupaciones elementales (G-9) presentan el mayor porcentaje de casos; las proporciones

18 Ángela Maryoure Gigliola SuÁrez-Moya, Análisis de la calificación de pérdida de capacidad laboral por desórdenes musculoesqueléticos en miembro superior en una administradora de riesgos profesionales colombiana en el año 2008 (Tesis de grado, Universidad Nacional de Colombia, Bogotá, 2012). Disponible en: http://www.bdigital.unal.edu.co/11364/1/05598414.\%202012.pdf 
de reclamantes por AT y por EL son similares (36 y 37\%, respectivamente). Se aprecian mayores porcentajes de reclamantes por accidente de trabajo (AT) que por enfermedad laboral (EL) en los grupos 7 (operativos calificados), 8 (conductores y operarios de maquinaria) y 5 (comercio, protección y seguridad).

De otro lado, los grupos 4 y 2 (personal administrativo, profesional e intelectual) presentan mayores proporciones de reclamantes por enfermedad laboral (EL) que por accidente de trabajo (AT). En los demás grupos de ocupaciones, los reclamantes por ambos tipos de eventos son similares y muestran proporciones menores a $1 \%$.

Respecto a la actividad económica desarrollada por la empresa, en las industrias manufactureras (C), las empresas de producción agrícola (A) y las entidades de administración pública y defensa (O), la proporción de reclamantes por EL fue mayor que por AT.

Por otra parte, en las empresas de construcción $(\mathrm{F})$, transporte y almacenamiento $(\mathrm{H})$ y suministro de personal de apoyo $(\mathrm{N})$, la proporción de reclamaciones por AT superó la de EL. En las empresas dedicadas al comercio y/o reparación de vehículos $(G)$ y en las compañías de explotación minera, petroleras y canteras, las proporciones de reclamo por AT y EL son iguales.

En las enfermedades laborales (EL), el 90\% de los casos corresponde a la categoría CIE-10 de enfermedades del sistema osteomuscular y tejido conjuntivo; son representativas como diagnóstico general las afecciones de columna vertebral y entre estas, la afectación lumbar (93\%). Estas estadísticas muestran los mismos patrones reportados por las aseguradoras de riesgos laborales en la segunda encuesta de condiciones de seguridad y salud en el trabajo en el sistema de riesgos laborales para el período 2009-2012 ${ }^{19}$.

Estos hallazgos orientan respecto a qué factores deben intervenirse prioritariamente en las acciones de promoción de la seguridad y salud y prevención de los riesgos laborales que está contemplado en el Plan Nacional de Seguridad y Salud en el Tra-

19 Colombia, Ministerio del Trabajo \& Organización Iberoamericana de Seguridad Social, OISS, Informe Ejecutivo, II Encuesta Nacional de Condiciones de Seguridad y Salud en el Trabajo en el Sistema General de Riesgos Laborales (Ministerio del Trabajo, Bogotá, 2013). Disponible en: http:// ccs.org.co/salaprensa/images/Documentos/INFORME_EJECUTIVO_II\%20ENCSST.pdf 
bajo (2013-2021) 20 21 Las afecciones de columna vertebral son el principal diagnóstico osteomuscular de origen laboral calificado por la Junta Nacional; esto es congruente con lo reportado en otros países, hace necesario que se realicen esfuerzos en la prevención de discapacidad derivada de este diagnóstico y se revisen experiencias internacionales y grupos de investigación que llevan trabajando en este tema más de 20 años ${ }^{22} 23$.

Otras categorías del CIE-10 que ocuparon el restante 10\% de diagnósticos se referían a los trastornos mentales y del comportamiento (4\%), entre los que se destacan los trastornos y episodios depresivos, en el $47 \%$ de los reclamantes con esta categoría y los trastornos mixtos de ansiedad y depresión, en el 26\% de los casos. Esto es congruente con el aumento mundial de enfermedad mental, y que ha sido una de la preocupaciones de la Organización para la Cooperación y el Desarrollo Económicos (OCDE) ${ }^{24}$, lo que ha incentivado la investigación referente a cuáles deberían ser las estrategias para mejorar el funcionamiento laboral de estos trabajadores y permitirles retornar al trabajo o mantener su productividad y bienestar ${ }^{25}$.

20 Colombia, Ministerio del Trabajo, Plan Nacional de Seguridad y Salud en el Trabajo 2013-2021 (Ministerio del Trabajo, Bogotá, 2014). Disponible en: http://www.oiss.org/IMG/pdf/PlanNacional DeSeguridadySaludEnElTrabajo.pdf

21 Colombia, Ministerio del Trabajo, Resolución 06045 de 2014, por la cual se adopta el Plan Nacional de Seguridad y Salud en el Trabajo 2013-2021, 30 de diciembre de 2014. Disponible en: http://www. mintrabajo.gov.co/normatividad/resoluciones/2014/700-diciembre-2014/4214-resolucion-06045-. html

22 John Frank, Sandra Sinclair, Sheilah Hogg-Johnson, Harry Shannon, Claire Bombardier, Dorcas Beaton \& Donald Cole, Preventing Disability from Work-Related Low-Back Pain. New Evidence Gives New Hope - If We Can Just Get All the Players Onside, 158 Canadian Medical Association Journal, 12, 1625-1631 (1998). Disponible en: https:/www.ncbi.nlm.nih.gov/pmc/ articles/PMC1229415/pdf/cmaj_158_12_1625.pdf

23 Johannes R. Anema, Antonius J. M. Schellart, J. D. Cassidy, Patrick Loisel, T. J. Veerman \& Allard J. VAN DER BEEK, Can Cross Country Differences in Return-To-Work after Chronic Occupational Back Pain Be Explained? An Exploratory Analysis on Disability Policies in a Six Country Cohort Study, 19 Journal of Occupational Rehabilitation, 4, 419-426 (2009). Disponible en: http://www. pubmedcentral.nih.gov/articlerender.fcgi?artid=2775112\&tool=pmcentrez\&rendertype $=$ abstract

24 Organisation for Economic Co-operation and Development, OECD, Fit Mind, Fit Job: From Evidence to Practice in Mental Health and Work (OECD Publishing, Paris, 2015). Disponible en: http://www. oecd.org/els/fit-mind-fit-job-9789264228283-en.htm

25 Andrea D. Furlan, William H. Gnam, Nancy Carnide, Emma Irvin, Benjamin C. Amick, Kelly DeRango, Robert McMaster, Kimberley Cullen, Tesha Slack, Sandra Brouwer \& Ute BültMANN, Systematic Review of Intervention Practices for Depression in the Workplace, 22 Journal of Occupational Rehabilitation, 3, 312-321 (2012). Disponible en: http://download.springer.com/static/ pdf/481/art\%253A10.1007\%252Fs10926-011-9340-2.pdf?originUrl=http\%3A\%2F\%2Flink.springer. com $\% 2$ Farticle $\% 2 F 10.1007 \% 2 F s 10926-011-9340-2 \&$ token $2=\exp =1497660777 \sim$ acl $=\% 2 \mathrm{Fstatic} \% 2 \mathrm{~F}$ pdf\%2F481\%2Fart\%25253A10.1007\%25252Fs10926-011-9340-2.pdf\%3ForiginUrl\%3Dhttp\%253A 
Colombia es uno de los países líderes en Iberoamérica en la prevención de enfermedad por riesgo psicosocial laboral; esto ha motivado en parte el aumento en el número de casos de enfermedad mental en el sistema de riesgos, debido a que ahora se cuenta con mayor conocimiento por parte de los actores, lo que propicia el reporte.

Las enfermedades del oído y la apófisis mastoides figuran también con $4 \%$ de reclamantes, con hipoacusia de diferente clasificación en 90\% de ellos. Las enfermedades del sistema respiratorio aparecen como categoría CIE-10 en el $2 \%$ de los casos de enfermedad laboral reclamados. Con porcentajes inferiores a $1 \%$, se reportan casos de enfermedades del sistema nervioso, del ojo y sus anexos, de la piel y neoplasias, entre otros. Aquí es importante aclarar que, a pesar de los esfuerzos del Ministerio del Trabajo en asocio con el Instituto Nacional de Cancerología en actualizar el plan de prevención para cáncer ocupacional, aún hay subregistro y falta de capacitación en los profesionales de salud encargados de la calificación de origen en las entidades de seguridad social. Al revisar - ahora - los eventos de reclamación de accidente de trabajo remitidos a la JNC, el $86 \%$ de los casos presenta como categoría CIE-10 las lesiones, heridas, intoxicaciones y otros factores externos; la fractura es la lesión de mayor proporción $(36 \%)$.

Las alteraciones osteomusculares fueron catalogadas como diagnóstico de accidente de trabajo en el 7\% de los casos reclamados y en porcentajes menores a 3 y $2 \%$, aparecen las alteraciones nerviosas y afecciones del ojo y sus anexos.

De acuerdo con los casos laborales recibidos en la JNC y los registros de Fasecolda (promedio de afiliados de 2007 a 2014), se presenta la proporción de eventos que deben ser correlacionados.

\section{B. Correlación de datos de la JNC y los de Fasecolda}

Llama la atención que solo $1 \%$ de los casos de accidente de trabajo llegan a la $\mathrm{JNC}$, mientras una de cada tres enfermedades laborales lo hace. Esto se explica porque al ser el accidente de trabajo un evento súbito en el que es más fácil definir si cumple o no los criterios legales

$\% 252 \mathrm{~F} \% 252 \mathrm{Flink}$.springer.com $\% 252$ Farticle $\% 252 \mathrm{~F} 10.1007 \% 252 \mathrm{Fs} 10926-011-9340-2 * \mathrm{hmac}=\mathrm{cfb}$ 2149f7703399d54ee5df17312a5d3fcf8811fd18052252877638f297e14f1 
para ser calificado como tal, hay menos controversia; en cambio, la enfermedad laboral, por su fisiopatología, generalmente toma varios años en producirse y crea la necesidad de aclarar factores extralaborales asociados a la génesis, genera que haya mayor divergencia entre los conceptos de las empresas promotoras de salud y las administradoras de riesgos laborales; esto obliga a acudir a las juntas de calificación, para determinar en última instancia el origen.

Más de un cuarto de los casos de incapacidad permanente parcial que paga Fasecolda, tuvieron que ser definidos en la Junta Nacional de Calificación de Invalidez, hecho que es diferente a la prestación de invalidez en la cual el porcentaje asciende a casi la mitad de los casos; esto se explica porque al ser una prestación vitalicia con altos costos para las aseguradoras y con un impacto social sobre los trabajadores, se genera mayor controversia por parte de los interesados.

\section{CARACTERÍSTICAS SOCIODEMOGRÁFICAS DE LOS CASOS LABORALES CALIFICADOS CON INCAPACIDAD PERMANENTE PARCIAL POR LA JUNTA NACIONAL DE CALIFICACIÓN DE INVALIDEZ 2007-2014}

Finalmente, se caracterizó el grupo de trabajadores a los que la Junta Nacional de Calificación de Invalidez les otorgó una pérdida de capacidad laboral entre el 5 y 49,9\% (Incapacidad Permanente Parcial, IPP). Se consideró importante analizar esta población, que, siendo económicamente activa, puede tener discapacidad para trabajar y sobre la cual se deben reforzar los esfuerzos investigativos para aportar soluciones tendientes a lograr que mantengan una opción ocupacional acorde a las condiciones de funcionamiento.

La segunda encuesta de condiciones de seguridad y salud en el trabajo en el sistema de riesgos laborales para el período 2009-2012, no indagó sobre este aspecto, por lo cual esta información aporta al conocimiento de la población en mayor riesgo de presentar discapacidad para trabajar (imposibilidad de retornar o mantenerse en el trabajo), en el sistema de riesgos laborales ${ }^{26}$.

26 Colombia, Ministerio del Trabajo \& Organización Iberoamericana de Seguridad Social, OISS, Informe Ejecutivo, II Encuesta Nacional de Condiciones de Seguridad y Salud en el Trabajo en el 
Perfil sociodemográfico: El 77\% de las personas calificadas con IPP corresponde al género masculino.

Por grupo de edad de notificación, las personas entre los 28 y los 57 años representan el $85 \%$ de los calificados con algún porcentaje de IPP por enfermedad laboral o accidente de trabajo.

El porcentaje más alto de nivel educativo corresponde al grupo de secundaria, reportado por el $43 \%$ de las personas que sufrieron evento laboral y fueron calificadas con IPP, mientras el más bajo lo ocupa el de estudios de posgrado $(0,3 \%)$.

En dos de cada tres casos, el reclamante calificado con IPP (incapacidad permanente parcial) vive en pareja, bien sea casado o en unión libre. Esto refuerza lo reportado con relación a que los factores personales, incluida la familia, juegan un papel importante en la posibilidad de tener procesos de reincorporación exitosos, por lo que los lineamientos y programas de rehabilitación deben incluir el ámbito familiar, con el concurso de varios sectores, no solo las administradoras de riesgos laborales.

Perfil ocupacional: Para analizar de manera más objetiva el perfil ocupacional de quienes presentaron contingencia laboral (ATEL) y fueron calificados con IPP, se tomaron como referencia la agrupación de cargos de la Clasificación Internacional Uniforme de Ocupaciones CIUO-08 y la Resolución 000139 de la DIAN, que adapta la Clasificación de Actividades Económicas, CIIU ${ }^{27}$.

En cerca del 4\% de los calificados con IPP, no se identifica la ocupación del reclamante, bien sea por carecer del dato o por tratarse de una diligencia por sustitución pensional, pensionado o estudiante. Este hallazgo se explica también por la ausencia de un sistema de información estandarizado.

Sistema General de Riesgos Laborales (Ministerio del Trabajo, Bogotá, 2013).

27 Colombia, Dirección de Impuestos y Aduanas Nacionales, DIAN, Resolución 000139 de 2012, por la cual la Dirección de Impuestos y Aduanas Nacionales - DIAN, adopta la Clasificación de Actividades Económicas - CIIU revisión 4 adaptada para Colombia, 21 de noviembre de 2012. Disponible en: http://www.dian.gov.co/descargas/normatividad/2012/Resoluciones/Resolucion_000139_21_ Noviembre_2012_Actividades_Economicas.pdf 


\section{Tabla 6}

\section{Agrupación de cargos de la Clasificación Internacional Uniforme de Ocupaciones, CIUO-08}

\begin{tabular}{|l|l|}
\hline G-9 & $\begin{array}{l}\text { Ocupaciones elementales: limpiadores, peones (agrícolas, minería, } \\
\text { construcción), ayudantes, recolectores de desechos, vendedores ambulantes } \\
\text { y afines }\end{array}$ \\
\hline G-8 & Operadores de maquinaria, ensambladores, conductores \\
\hline G-7 & $\begin{array}{l}\text { Oficiales y operarios de construcción y metalurgia, artes gráficas, } \\
\text { electricidad, alimentos, confección }\end{array}$ \\
\hline G-6 & Trabajadores agrícolas y forestales calificados \\
\hline G-5 & Trabajadores de comercio, cuidados personales y protección y seguridad \\
\hline G-4 & $\begin{array}{l}\text { Personal de apoyo administrativo: oficinistas, analistas, trato directo con el } \\
\text { público }\end{array}$ \\
\hline G-3 & $\begin{array}{l}\text { Profesionales y técnicos de nivel medio de la salud, financieros, jurídicos, } \\
\text { comunicación y cultural }\end{array}$ \\
\hline G-2 & Profesionales, científicos, intelectuales \\
\hline G-1 & $\begin{array}{l}\text { Personal directivo, administración pública, poder ejecutivo y legislativo, } \\
\text { gerentes }\end{array}$ \\
\hline G-0 & Oficiales, suboficiales y otros miembros de las fuerzas armadas \\
\hline
\end{tabular}

Fuente: Clasificación Internacional Uniforme de Ocupaciones, CIUO-08, adaptada para Colombia, CIU, Departamento Nacional de Estadísticas, DANE, 2005.

Tres cuartas partes de los casos registrados (77\%) corresponden a personas que desempeñan labores no calificadas en la construcción, la minería, la agricultura, el transporte, la fabricación de productos, oficios de limpieza y recolección de desechos. Este hallazgo genera muchos interrogantes: ¿será que hay una inequidad en los procesos de rehabilitación brindados por las administradoras de riesgos laborales, en los que se brindan mejores servicios de rehabilitación a trabajadores de empresas con mayor cotización? ¿Será que por el tipo de labor desarrollada y la baja tecnificación hay mayor severidad de los accidentes en este tipo de empresas, lo que conlleva mayores posibilidades de presentar incapacidad permanente parcial? ¿Será que a pesar de que se presten adecuados servicios de rehabilitación funcional, hay debilidad en los procesos de reintegro o acomodación laboral en empresas con labores no calificadas? ¿ Será que a pesar de los esfuerzos de los equipos de rehabilitación, se requiere una política de retorno al trabajo intersectorial que involucre a otros sectores como los empresarios, los sindicatos, el sector educación, las cajas de compensación, el Ministerio de Hacienda, el Servicio 
Nacional de Aprendizaje, SENA, las agencias de empleo, entre otras agencias y entidades gubernamentales?

Los más bajos valores corresponden a los grupos de cargos militares (G0), oficios agrícolas calificados (G6) y personal que ocupa cargos directivos y gerenciales (G1). Este hallazgo se explica primero porque la Junta Nacional de Calificación de Invalidez no es el ente competente para conocer los casos de las Fuerzas Militares acorde al Decreto 1352 de 2013 y solo los califica en casos de peritaje a solicitud de un juez. También se explica porque en su mayoría las empresas del sector agrícola no tienen contratos formales, lo que causa inequidad en cuanto a la posibilidad de estar afiliado al sistema de riesgos laborales, lo que hace que la proporción de casos con indemnización permanente parcial en este tipo de cargos sea baja dentro del sistema.

Uno de cada cuatro reclamantes calificados con IPP (25\%) corresponde al sector manufacturero $(\mathrm{C})$. Las empresas de suministro de personal de apoyo $(\mathrm{N})$, del sector comercial y de reparación mecánica $(\mathrm{G})$ y de construcción $(\mathrm{F})$ ocupan los siguientes lugares por proporción de personas calificadas con IPP. Por ser Colombia un país cuyo sector manufacturero tiene una alta proporción de pequeña y mediana empresa, es posible que estos sectores tengan mayor dificultad para cumplir las recomendaciones laborales tendientes a reincorporar al trabajador. Por esto se requiere que las administradoras de riesgos laborales realicen un mayor acompañamiento y seguimiento a los procesos de rehabilitación integral en este tipo de empresas.

Hasta aquí se presenta este panorama, que debe ser entendido como un primer esfuerzo por brindar estadísticas nacionales que permitan esquematizar las características sociodemográficas de las personas afiliadas al sistema de riesgos laborales colombiano. Aunque constituyen una pequeña fuente, dado que se originan solamente de las que son calificadas por la Junta Nacional de Calificación de Invalidez, tanto en origen como en pérdida de capacidad laboral, sí podrían marcar alertas importantes de lo que está sucediendo en el país.

Se espera que a futuro, el Ministerio del Trabajo priorice una línea de investigación en esta dirección, para que se puedan desarrollar estudios epidemiológicos de asociaciones de causalidad, 
además de indagar sobre factores relacionados con la discapacidad para trabajar, entre otros aspectos que permitan el mejoramiento del sistema de riesgos laborales.

Sin lugar a dudas, la ausencia de cifras pone en riesgo el monitoreo y evaluación de las iniciativas del Sistema de Riesgos Laborales, y de su implementación. No es suficiente elaborar un marco normativo, como la Ley 776 de 2002, Ley 1562 de 2012 y Decreto 1072 de $2015^{28}$, si no se hace seguimiento de la manera como el Sistema en su conjunto cumple los derechos consagrados, ni tampoco si se determina con claridad el rol que debe cumplir cada actor. Contar con un sistema de información del Sistema de Riesgos Laborales constituye un paso importante para alcanzar las metas esperadas; no tener cifras es no tener la posibilidad de saber si realmente se está cumpliendo lo prometido. Este asunto no da espera: debe entrar en la agenda de prioridades del país y de la región.

28 Colombia, Decreto 1072 de 2015, por medio del cual se expide el Decreto Único Reglamentario del Sector Trabajo, 49.523 Diario Oficial, 26 de mayo de 2015. Disponible en: http:/www.icbf.gov.co/ cargues/avance/docs/decreto_1072_2015.htm 


\section{BIBLIOGRAFÍA}

\section{Libros}

Arenas-Monsalve, Gerardo, El derecho colombiano de la seguridad social [Internet] (Legis, Bogotá, 2011). Disponible en: http://ezproxy.unal.edu.co/login?url=http:// search.ebscohost.com/login. aspx?direct $=$ true $\& d b=$ cat $02704 a \& A N=$ unc .00042 4417\&lang=es\&site $=$ eds-live

Cortés-González, Juan Carlos, Régimen de los riesgos laborales en Colombia: comentarios a la Ley 1562 de 2012 [Internet] (Legis, Bogotá, 2012). Disponible en: http://ezproxy.unal.edu.co/login?url=http://search.ebscohost.com/login.as px?direct $=$ true $\& \mathrm{db}=$ cat $02704 \mathrm{a} \& \mathrm{AN}=$ unc $.000455884 \&$ lang $=$ es $\&$ site $=$ eds-live

Moreno-Angarita, Marisol; Rubio, Sara Ximena \& Angarita-Rodríguez, Diana CRISTINA, Valoración de la pérdida de la capacidad laboral y ocupacional en Colombia: antecedentes, realidades y perspectivas de actualización [Internet] (Universidad Nacional de Colombia y Ministerio de la Protección Social, Bogotá, 2011). Disponible en: http://ezproxy.unal.edu.co/login?url=http:// search.ebscohost.com/login.aspx?direct $=$ true $\& d b=$ cat $02704 a \& A N=$ unc. 0 00669841\&lang=es\&site=eds-live, http://www.bdigital.unal.edu.co/42924/1/ saraximenarubio.2011.pdf

Organisation for Economic Co-operation and Development, OECD, Fit Mind, Fit Job: From Evidence to Practice in Mental Health and Work (OECD Publishing, Paris, 2015). Disponible en: http://www.oecd.org/els/fit-mind-fit-job-9789264228283-en. htm

\section{Revistas}

Anema, Johannes R.; Schellart, Antonius J. M.; Cassidy, J. D.; Loisel, Patrick; Veerman, T. J. \& Beek, Allard J. van der, Can Cross Country Differences in Return-To-Work after Chronic Occupational Back Pain Be Explained? An Exploratory Analysis on Disability Policies in a Six Country Cohort Study, 19 Journal of Occupational Rehabilitation, 4, 419-426 (2009). Disponible en: http:// www.pubmedcentral.nih.gov/articlerender.fcgi?artid=2775112\&tool=pmcentre $\mathrm{z} \&$ rendertype $=$ abstract

Frank, John; Sinclair, Sandra; Hogg-Johnson, Sheilah; Shannon, Harry; Bombardier, Claire; Beaton, Dorcas \& Cole, Donald, Preventing Disability from Work-Related Low-Back Pain. New Evidence Gives New Hope - If We Can Just Get All the Players Onside, 158 Canadian Medical Association Journal, 12, 1625-1631 (1998). Disponible en: https://www.ncbi.nlm.nih.gov/pmc/articles/ PMC1229415/pdf/cmaj_158_12_1625.pdf

Furlan, Andrea D.; Gnam, William H.; Carnide, Nancy; Irvin, Emma; Amick, Benjamin C.; DeRango, Kelly; McMaster, Robert; Cullen, Kimberley; Slack, Tesha; Brouwer, SANDra \& Bültmann, Ute, Systematic Review of Intervention Practices for Depression in the Workplace, 22 Journal of Occupational Rehabilitation, 3, 312321 (2012). Disponible en: http://download.springer.com/static/pdf/481/art\%253A 10.1007\%252Fs10926-011-9340-2.pdf?originUrl=http $\% 3 \mathrm{~A} \% 2 \mathrm{~F} \% 2 \mathrm{Flink}$.springer. 
com $\% 2$ Farticle $\% 2$ F10.1007\%2Fs10926-011-9340-2\&token $2=\exp =1497660777 \sim$ ac $1=\% 2$ Fstatic $\% 2 F p d f \% 2 F 481 \% 2$ Fart $\% 25253 \mathrm{~A} 10.1007 \% 25252 \mathrm{Fs} 10926-011-9340-2$. pdf $\% 3$ ForiginUrl $\% 3$ Dhttp $\% 253 \mathrm{~A} \% 252 \mathrm{~F} \% 252$ Flink.springer.com $\% 252$ Farticle $\%$ 252F10.1007\%252Fs10926-011-9340-2* $\sim \mathrm{hmac}=\mathrm{cfb} 2149 \mathrm{f} 7703399 \mathrm{~d} 54 \mathrm{ee} 5 \mathrm{df} 17312 \mathrm{a} 5$ d3fcf8811fd18052252877638f297e14f1

Gutiérrez-Strauss, Ana María, Rehabilitación integral y reincorporación: su incidencia en el ausentismo laboral, 12 Revista de la Sociedad Colombiana de Medicina del Trabajo, 1, 8-11 (2009).

Vélez-Arango, Alba Lucía, Salud y enfermedad: la contribución de la Corte Constitucional de Colombia, 17 Hacia la Promoción de la Salud, 2, 91-109. Disponible en: http:// ezproxy.unal.edu.co/login?url=http://search.ebscohost.com/login.aspx?direct=t rue \&db=a9h\&AN=90416424\&lang=es\&site=eds-live, http://www.scielo.org.co/ $\mathrm{pdf} / \mathrm{hpsal} / \mathrm{v} 17 \mathrm{n} 2 / \mathrm{v} 17 \mathrm{n} 2 \mathrm{a} 07 . \mathrm{pdf}$

\section{Normatividad colombiana}

Colombia, Decreto 2644 de 1994, por el cual se expide la Tabla Única para las indemnizaciones por pérdida de la capacidad laboral entre el $5 \%$ y $49.99 \%$ y la prestación económica correspondiente, 41.620 Diario Oficial, 30 de noviembre de 1994. Disponible en: http://www.suin-juriscol.gov.co/clp/contenidos.dll/ Decretos $/ 1475751 ? \mathrm{fn}=$ document-frame.htm $\$ \mathrm{f}=$ templates $\$ 3.0$

Colombia, Decreto 917 de 1999, por el cual se modifica el Decreto 692 de 1995, 43.601 Diario Oficial, 9 de junio de 1999. Disponible en: http://www.suin-juriscol.gov. co/viewDocument.asp?id=1798298

Colombia, Decreto 1352 de 2013, por el cual se reglamenta la organización y funcionamiento de las Juntas de Calificación de Invalidez, y se dictan otras disposiciones, 48.834 Diario Oficial, 27 de junio de 2013. Disponible en: http:// www.suin-juriscol.gov.co/viewDocument.asp?id=1271832

Colombia, Decreto 1507 de 2014, por el cual se expide el Manual Único para la Calificación de la Pérdida de la Capacidad Laboral y Ocupacional, 49.241 Diario Oficial, 12 de agosto de 2014. Disponible en: http://www.suin-juriscol.gov.co/clp/ contenidos.d1l/Decretos $/ 30030556$ ? $\mathrm{fn}=$ document-frame.htm $\$ \mathrm{f}=$ templates $\$ 3.0$

Colombia, Decreto 1072 de 2015, por medio del cual se expide el Decreto Único Reglamentario del Sector Trabajo, 49.523 Diario Oficial, 26 de mayo de 2015. Disponible en: http://www.icbf.gov.co/cargues/avance/docs/decreto_1072_2015. htm

Colombia, Dirección de Impuestos y Aduanas Nacionales, DIAN, Resolución 000139 de 2012, por la cual la Dirección de Impuestos y Aduanas Nacionales - DIAN, adopta la Clasificación de Actividades Económicas - CIIU revisión 4 adaptada para Colombia, 21 de noviembre de 2012. Disponible en: http://www.dian. gov.co/descargas/normatividad/2012/Resoluciones/Resolucion_000139_21_ Noviembre_2012_Actividades_Economicas.pdf

Colombia, Ley 776 de 2002, por la cual se dictan normas sobre la organización, administración y prestaciones del Sistema General de Riesgos Profesionales, 45.037 Diario Oficial, 17 de diciembre de 2002. Disponible en: http://www. 
secretariasenado.gov.co/senado/basedoc/ley_0776_2002.html

Colombia, Ley 1562 de 2012, por la cual se modifica el Sistema de Riesgos Laborales y se dictan otras disposiciones en materia de salud ocupacional, 48.488 Diario Oficial, 11 de julio de 2012. Disponible en: http://www.secretariasenado.gov.co/ senado/basedoc/ley_1562_2012.html

Colombia, Ministerio del Trabajo, Resolución 06045 de 2014, por la cual se adopta el Plan Nacional de Seguridad y Salud en el Trabajo 2013-2021, 30 de diciembre de 2014. Disponible en: http://www.mintrabajo.gov.co/normatividad/ resoluciones/2014/700-diciembre-2014/4214-resolucion-06045-.html

\section{Documentos, informes, manuales, reportes, tesis}

Colombia, Federación de Aseguradores Colombianos, Fasecolda, Enfermedad laboral en Colombia. Debate en Salud Pública sobre enfermedad laboral (Federación de Aseguradores Colombianos, Fasecolda, Bogotá, 2013).

Colombia, Ministerio de la Protección Social, Manual de procedimientos para la rehabilitación y reincorporación ocupacional de los trabajadores en el Sistema General de Riesgos Profesionales (Ministerio de la Protección Social, Bogotá, 2010). Disponible en: http://fondoriesgoslaborales.gov.co/documents/ Publicaciones/Manuales/MANUAL-PARA-REHABILITACION-2012.pdf

Colombia, Ministerio del Trabajo, Plan Nacional de Seguridad y Salud en el Trabajo 2013-2021 (Ministerio del Trabajo, Bogotá, 2014). Disponible en: http://www. oiss.org/IMG/pdf/PlanNacionalDeSeguridadySaludEnElTrabajo.pdf

Colombia, Ministerio del Trabajo \& Organización Iberoamericana de Seguridad Social, OISS, Informe Ejecutivo, II Encuesta Nacional de Condiciones de Seguridad y Salud en el Trabajo en el Sistema General de Riesgos Laborales (Ministerio del Trabajo, Bogotá, 2013). Disponible en: http://ccs.org.co/salaprensa/images/ Documentos/INFORME_EJECUTIVO_II\%20ENCSST.pdf

Organización Iberoamericana de Seguridad Social, OISS, Recopilación de los principales indicadores de siniestralidad laboral y enfermedad ocupacional utilizados en Iberoamérica (2012). Disponible en: http://www.oiss.org/estrategia/IMG/pdf/ Informe_sobre_siniestralidad.pdf

SuÁrez-Moya, Ángela Maryoure Gigliola, Análisis de la calificación de pérdida de capacidad laboral por desórdenes musculoesqueléticos en miembro superior en una administradora de riesgos profesionales colombiana en el año 2008 (Tesis de grado, Universidad Nacional de Colombia, Bogotá, 2012). Disponible en: http:// www.bdigital.unal.edu.co/11364/1/05598414.\%202012.pdf 
